\title{
Effects of Plasma Activated Water on the Postharvest Quality of 'Siberia' Lily
}

\author{
Song Kwon ${ }^{1}$ and Ju Hyun Ryu ${ }^{2} *$ \\ ${ }^{1}$ Research Institute of Agriculture and Life Science, Seoul National University, Seoul 08826, South Korea \\ ${ }^{2}$ Siheung City Agriculture Technology Center, Siheung City, Gyeonggi-do 14998, South Korea
}

\begin{abstract}
This study was carried out to determine the effect of plasma activated water (PAW) on the postharvest quality of Lilium Oriental Hybrid cv. Siberia. Time-dependent concentration of hydrogen peroxide generated by underwater plasma apparatus was measured. Plasma activated water containing hydrogen peroxide was used as preservative solution and concentration of hydrogen peroxide was 300,600, and $900 \mu \mathrm{M}$ (PAW300, PAW600, and PAW900), respectively. The amount of hydrogen peroxide in the plasma activated water increased with increasing the discharge time. Plasma activated water extended flower longevity of 'Siberia' lily more than control. The results of this study show that PAW600 caused an increase in flower longevity, maximum flower diameter, and water uptake. The decline of fresh weight, loss of leaf relative water, and loss of leaf chlorophyll content were also reduced by PAW600 treatment. With increasing the discharged time, the microbial growth in the preservative solution was effectively suppressed, which depends on the concentration of hydrogen peroxide in the plasma activated water. In conclusion, PAW600 treatment could extend flower longevity by suppressing microbial growth in the preservative solution. Therefore, it was concluded that the use of PAW600 as a preservative solution was effective in improving the postharvest quality of cut lily flowers.
\end{abstract}

Keywords: Hydrogen peroxide, Lilium Oriental hybrid, Postharvest treatment, Preservative solution, Senescence

\section{Introduction}

Plasma is referred to as the fourth state of matter distinct from solids, liquids and gases, and it is consisted of neutral particles, approximately equal numbers of positively charged ions and negatively charged electrons. (Lee and Cho, 2013). Plasma is an ionized gas that can be applied to seteilization and various fields by generating high concentration reactive species. This is also an eco-friendly technology that does not produce any by-products in the process of generating a plasma. In agricultural fields, plasma technologies have been used radicals in the gaseous state that are generated in the plasma state. However, there is a problem that heat is applied to the object or the part that is not in contact with the gas is not treated. In order to address this issue found in the process of treating the plasma in the gaseous state, studies have

This work was supported by the Korea Institute of Planning and Evaluation for Technology in Food, Agriculture and Forestry (IPET) through the Agri-Bio Industry Technology Development Program (115087-2) funded by the Ministry of Agriculture, Food and Rural Affairs (MAFRA), and the National Research Foundation of Korea (NRF) and the Center for Women in Science, Engineering and Technology (WISET) Grant funded by the Ministry of Science and ICT under the program for Returner into R\&D (WISET-2017-592).

Received: February 24, 2018, Revised: February 28, 2018, Accepted: February 28, 2018

First author: Song Kwon, E-mail: freesia77@empal.com, ORCID: 0000-0002-3190-7217

*Corresponding author: Ju Hyun Ryu, E-mail: snuqb12@snu.ac.kr, ORCID: 0000-0002-6209-5098

C 2018 by the Society for People, Plants, and Environment. This is an Open Access article distributed under the terms of the Creative Commons Attribution Non-Commercial License (http://creativecommons.org/licenses/by-nc/4.0/) which permits unrestricted non-commercial use, distribution, and reproduction in any medium, provided the original work is properly cited. 
recently been carried out on methods of dissolving radicals generated in the plasma in a liquid for long term storage of the active radical (Uhm et al., 2006). In order to generate and maintain such a plasma, a magnetic field is required for electrons to get energy. Accordingly, research has been conducted to develop various power supply equipment that can generate an electric field and supply energy to plasma according to the needs of users and the properties of plasma (Lee and Cho, 2013).

Freshness is particularly important to cut flowers. Since maintaining freshness is directly connected to the marketability and price of cut flowers, comprehensive measures to maintain freshness need to be established for each stage of distribution. There are three major factors that reduce the postharvest quality of cut flowers during distribution: the generation of ethylene (a senescence hormone produced during distribution), the respiration of flowers induced by temperature, and the propagation of microorganisms. The cut surface of the stem of cut flowers is often decayed due to the propagation of microorganisms or the function of their vessels are damaged due to the inflow of air, which deters the absorption of water and thus significantly shortens the vase life of cut flowers (Teixeira da Silva, 2003; van Doorn, 1997). For this reason, cut flowers are pre-treated to increase their ability to absorb water right after being harvested or post-treated with a preservative solution mixed with nutrients or bactericides in order to maintain their freshness (Fanourakis et al., 2013; Yoo et al., 2003).

There are a couple of methods of producing plasma-activated water using radicals produced in the plasma state such as a method of using microwave plasma and a method of producing plasma in water. Out of them, the underwater plasma technique resolves water with plasma that is produced by electrodes in water and creates reactive oxygen species (ROSs), and they react with water to produce hydrogen peroxide, and thus become bactericidal (Hong et al., 2010; Ma et al., 2017). Taking advantages of these properties, plasma-activated water can be used as a pre- and post-treatment solution to improve cut flowers ability to absorb water, to maintain water balance in the plant body and thus to effectively prolong their vase life. In this regard, this study was conducted to assess the properties of plasma-activated water and the postharvest quality of Lilium Oriental Hybrid cv. Siberia, and to examine the possibility of utilizing plasma-activated water as a preservative solution for cut flowers.

\section{Methods}

\section{Materials}

Cut flowers of Lilium Oriental hybrid 'Siberia' were tested to examine the effects of plasma-activated water on maintaining the freshness of flowers. Cut lily flowers of which stem has one colored flower bud and was harvested for the commercial purpose were purchased from a wholesale market.

\section{Equipment for the generation of plasma-activated water}

Plasma-activated water used in this study was produced using an underwater plasma apparatus that has capillary electrodes (NPAC Inc., Korea). Reactive oxygen species (ROSs) produced using a underwater plasma discharge technique have a very short half-life and it is difficult to measure them. For this reason, the properties of plasma-activated water were quantified based on the concentration of hydrogen peroxide. Using the underwater plasma apparatus, a $3 \mathrm{~L}$ tank equipped with an electrode was filled with $2 \mathrm{~L}$ of tap water, and changes in the amount of hydrogen peroxide produced depending on the electric discharge time and voltage $(120 \mathrm{~V})$ were measured. The concentration of hydrogen peroxide was measured using an ion chromatography (ICS5000, ThermoDionex, USA). Samples were injected using an autosampler 
(ThermoDionex), and were tested using a pulsed amperometry (ED40) and CarboPac_SA10 Analytical (4×250 mm, Dionex, USA) and CarboPac_SG10 Guard (4×50 mm, Dionex, USA) columns.

To identify the relationship between electric discharge time and the amount of hydrogen peroxide in plasma-activated water, a nonlinear regression analysis was performed (SigmaPlot 12.5, Germany) using an exponential function regression model: $\mathrm{y}=\mathrm{a}\left(1-\mathrm{e}^{-\mathrm{bx}}\right)$ (Exponential Rise to Maximum, Single, 2 Parameter).

\section{Preservative solution treated with underwater plasma-activated water}

'Siberia' lily purchased from the market was cut again to the length of $26 \mathrm{~cm}$, and leaves that touch water, except for two leaves for each stem, were removed. The cut flowers were put in a container filled with plasma-activated water ( $\mathrm{pH}$ 7.3) that was electrically discharged until the concentration of hydrogen peroxide reached 300, 600 and $900 \mu \mathrm{M}$, and their postharvest quality was assessed in a laboratory (temperature: $23 \pm 1^{\circ} \mathrm{C}$, relative humidity: $70 \pm 10 \%$, light: 9 hours per day). After that, the vase life of cut flowers, flower diameter, the amount of water absorbed, fresh weight, relative water content, and chlorophyll content were measured. The vase life of cut flowers was determined when flowers wither or fall, and thus lose their ornamental value. The longest diameter of cut flowers was measured using a caliper (ABS Digimatic Caliper, Mitutoyo Co., Ltd., Japan), and the total amount of water absorbed was measured 8 days after treatment. Fresh weight, relative water content and chlorophyll content were measured every two days. Fresh weight was expressed as a percentage of increase from the initial fresh weight. The relative water content in leaves was calculated using the following formula.

Relative water content $(\%)=($ FW-DW $) /($ TW-DW $) \times 100$

Where, FW is fresh weight, TW is turgid weight measured 12 hours after dipping cut flowers in distilled water, and DW is dry weight.

Chlorophyll content was measured in the middle part of the second leaf using a chlorophyll meter (SPAD-502, Konica-Minolta, Japan) and the test was repeated 5 times.

\section{Monitoring the amount of microorganisms generated in the preservative solution}

To assess the bactericidal activity of plasma-activated water, the amount of microorganisms generated in the preservative solution was measured. The preservative solution was serially diluted ten times with $9 \mathrm{~mL}$ of sterile saline solution, and 1 $\mathrm{mL}$ of each diluted solution was dispensed on a petrifilm aerobic count plate (3M, Seoul, Korea). Microorganisms were cultured at $30^{\circ} \mathrm{C}$ for $24-48$ hours, and the number of colonies created on the petrifilms was counted (colony-forming unit $(\mathrm{CFU}) / \mathrm{mL})$.

\section{Results and Discussion}

\section{Analysis of the properties of plasma-activated water}

There was no changes in $\mathrm{pH}$ and electrical conductivity depending on the voltage and time of underwater plasma discharge (data not shown). Since plasma is produced using water in the process of underwater discharge, activities such as ionization, vibration and rotation create reactive oxygen species (ROSs) associated with the basic components of water (hydrogen and oxygen) such as $\mathrm{O}^{-}, \mathrm{OH}^{-}$and $\mathrm{H}_{2} \mathrm{O}_{2}$. ROSs are later combined with $\mathrm{OH}$ radicals and produce hydrogen peroxide that is bactericidal (Ma et al., 2017). For this reason, standards for treating underwater plasma-activated water were set based on the concentration of hydrogen. The longer the time of electric discharge, the more hydrogen peroxide 


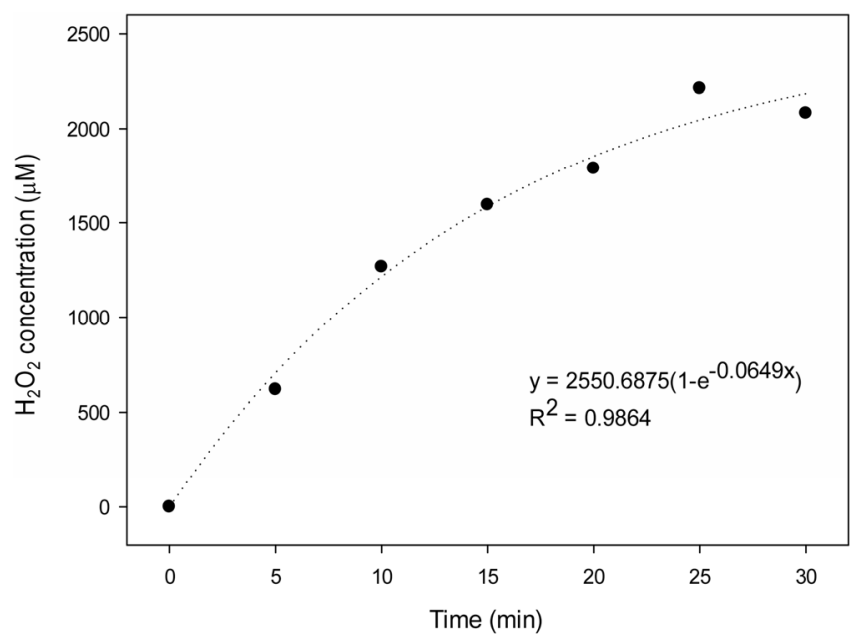

Figure 1. Time-dependent concentration of $\mathrm{H}_{2} \mathrm{O}_{2}$ generated by underwater plasma apparatus.

was produced. After 25 minutes of electric discharge with $120 \mathrm{~V}$ voltage, the amount of hydrogen peroxide produced reached the peak $(2,200 \mu \mathrm{M})$, and, after that, the amount continued to decrease (Fig. 1). The results of regression analysis showed that $300 \mu \mathrm{M}, 600 \mu \mathrm{M}$ and $900 \mu \mathrm{M}$ of hydrogen peroxide were generated after 1.9, 4.1 and 6.7 minutes respectively.

\section{Postharvest quality of cut flowers after treating with the preservative solution of plasma-activated water}

The vase life of cut flowers of 'Siberia' lily was measured to assess their postharvest quality after being treated with plasma-activated water (Fig. 2A). The vase life of the control group was the shortest, and the vase life of those treated with plasma-activated water that contained $300 \mu \mathrm{M}$ of hydrogen peroxide (PAW300) was slightly prolonged. Meanwhile, the vase life of those treated with plasma-activated water that contained $600 \mu \mathrm{M}$ of hydrogen peroxide (PAW600) was the longest (10.1 days), which was $15.7 \%$ longer than that of the control group. The vase life of those treated with plasmaactivated water that contained $900 \mu \mathrm{M}$ of hydrogen peroxide (PAW900) was similar to that of the PAW300 group. Recently, bioactive substances have started to be used in agricultural fields taking advantages of the defense mechanism of plants against stress. Hydrogen peroxide is known as a main factor that causes oxidative stress in plants, but it also plays a role, as a medium that responds to stress (Saxena et al., 2016), in improving tolerance to stress factors such as high temperature (Gao et al., 2010), salt (De Azevedo Neto et al., 2005) and heavy metals (Hu et al., 2009). Reactive oxygen species (ROSs) are also involved in the aging of flowers, and it was reported that the aging of daylily pedals was accelerated due to an increasing amount of ions caused by the treatment of hydrogen peroxide (Panavas and Rubinstein, 1998). Liao et al. (2012) reported that the vase life of cut flowers of 'Manissa', a hybrid lily species, was prolonged when they were treated with a preservative solution that contains a low concentration of hydrogen peroxide $(600 \mu \mathrm{M})$. Rahimian-Boogar et al. (2016) also reported that treating with an approximately $648 \mu \mathrm{M}$ concentration of hydrogen peroxide delayed browning and falling pedals and doubled the vase life of cut flowers of tuberose compared to that of the control group.

The flower diameter of cut flowers after treating with plasma-activated water was measured, and the results showed that there was no statistical significance in the maximum flower diameter between the control group and the experimental groups treated with plasma-activated water. The flower diameter of the experimental groups was slightly higher than that of the control group, and that of the PAW600 group was the largest (Fig. 2B). There are several factors that determine the 

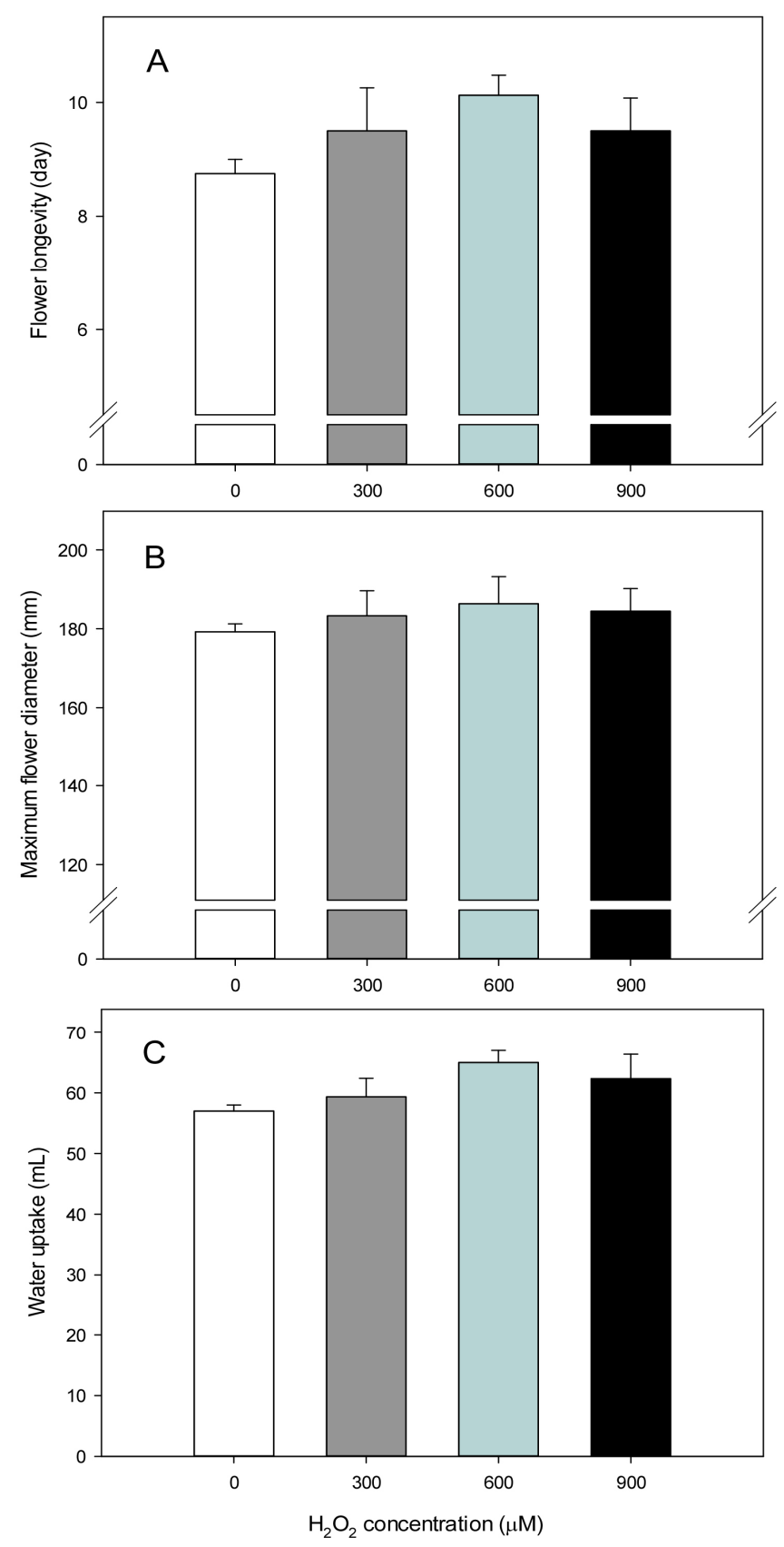

Figure 2. Effects of underwater plasma activated water on flower longevity (A), Maximum flower diameter (B), and water uptake (C) of 'Siberia' lilies. Data are the means \pm SD from five replications.

vase life of cut flowers, including the poor opening of flower buds and the partial blooming of flowers (van Doorn and Han, 2011), and, the results of the maximum flower diameter measured in this study showed that cut flowers treated with plasma-activated water were normally bloomed. Liao et al. (2012) reported that the maximum flower diameter of 'Manissa' lily treated with $600 \mu \mathrm{M}$ of hydrogen peroxide significantly increased compared to the control group, but the flower diameter of cut flowers treated with a high concentration of hydrogen peroxide $(1,200 \mu \mathrm{M})$ decreased. In the same study, when cut flowers were treated with $600 \mu \mathrm{M}$ of hydrogen peroxide, and ascorbic acid and diphenylene iodonium that were used as a hydrogen peroxide quencher and inhibitor respectively, the phenomenon was offset. The study also reported that treating flowers with a proper concentration of hydrogen peroxide delays the aging of flowers and also 
increases the diameter of flowers.

The amount of water absorbed by 'Siberia' lily treated with plasma-activated water was higher than that of the control group, and, in particular, that of the PAW600 group was $65.0 \mathrm{~mL}$, higher than that of the other treated groups (Fig. 2C). In a study on tuberose, the amount of water absorbed by flowers treated with $648 \mu \mathrm{M}$ of hydrogen peroxide increased (Rahimian-Boogar et al., 2016). In this study, cut flowers treated with plasma-activated water that contained $600 \mu \mathrm{M}$ of hydrogen peroxide had a higher ability to absorb water, which indicates that the treatment condition is very effective in maintaining water balance in the plant body.

'Siberia' lily in the control group bloomed and its fresh weight continued to increase to $116.5 \%$, but started to rapidly
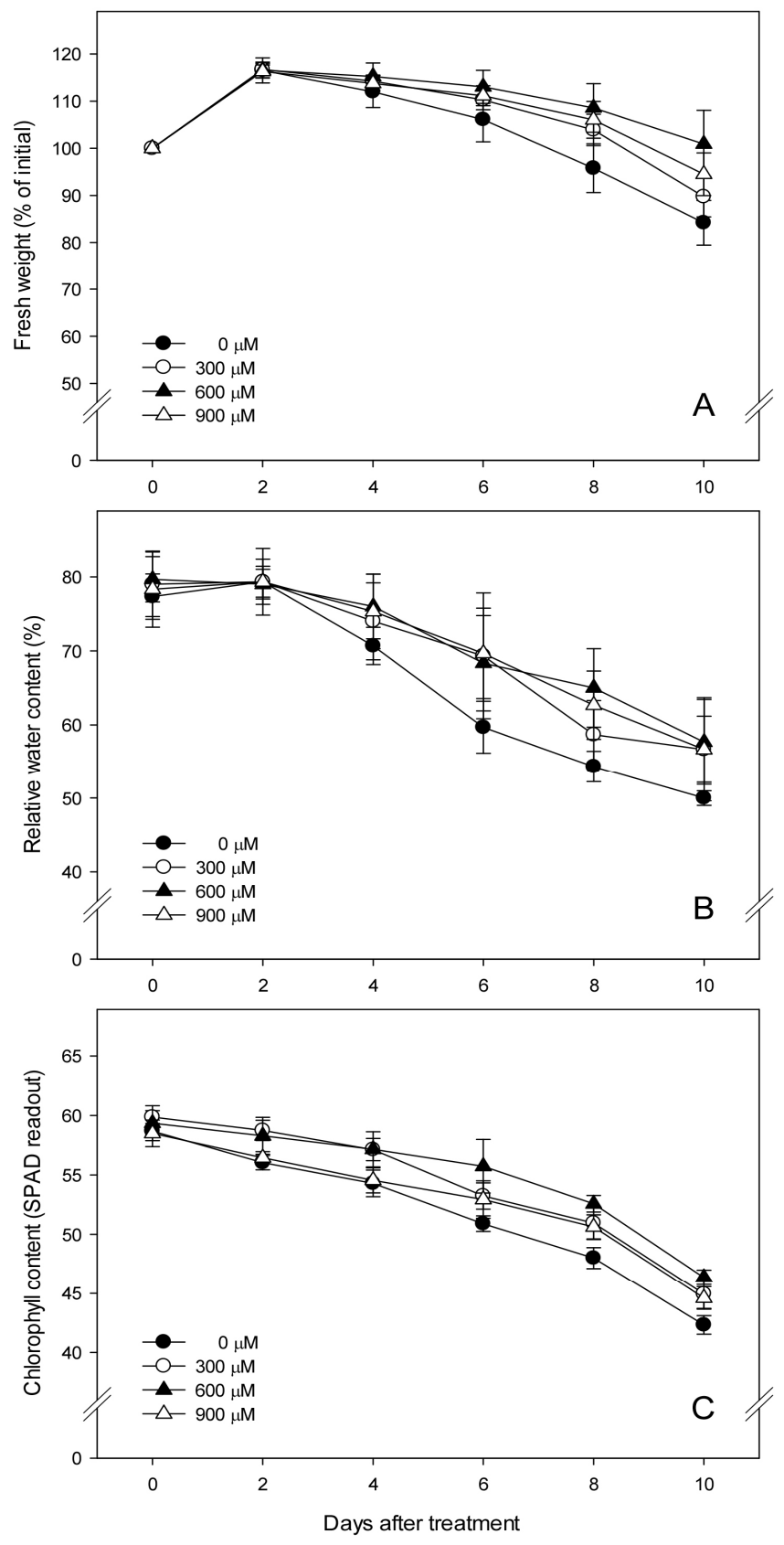

Figure 3. Effects of underwater plasma activated water on fresh weight (A), relative water content (B), and chlorophyll content $(C)$ of 'Siberia' lilies. Data are the means \pm SD from five replications.

98 - Journal of People, Plants, and Environment Vol. 21, No. 2, 2018 
decrease after 2 days, showing a lower fresh weight than that of the groups treated with plasma-activated water (Fig. 3A). The fresh weight of the treated groups also continued to increase until after 2 days, similar to the control group, but since then, their fresh weight started to slowly decrease in the order of $600 \mu \mathrm{M}, 900 \mu \mathrm{M}$ and $300 \mu \mathrm{M}$, maintaining a relatively high fresh weight. It is very important to ensure water flows smoothly, reduce a water loss and maintain a high fresh weight in order to prolong the vase life of cut flowers. Earlier studies on 'Manissa' lily and tuberose reported that treating with hydrogen peroxide is effective in reducing loss in fresh weight and prolonging the vase life of cut flowers (Liao et al., 2012; Rahimian-Boogar et al., 2016).

Relative water content in the leaves of 'Siberia' lily of the control group and the treated groups was maintained high until after 2 days, and started to decrease since then (Fig. 3B). Relative water content in the leaves of the control group started to rapidly decrease after 2 days, showing a lower relative water content than the groups treated with plasmaactivated water. Relative water content in the treated groups also started to decrease after 2 days, but the groups showed a lower decrease than the control group. In general, water conditions in plants are measured using the method used to measure the relative water content (Lee et al., 2011). It was also reported that relative water content in cut flowers decreases and water content is reduced as they are aging (Seo et al., 2009). In an earlier study, treating 'Manissa' lily with $600 \mu \mathrm{M}$ of hydrogen peroxide effectively delayed a decrease in relative water content in leaves, which was attributed to abscisic acid (ABA) that controls the closing of stomata and reduces a loss in water content in leaves (Liao et al., 2012). According to Saglam et al. (2014), when cut leaves of Ctenanthe setosa were pre-treated with $200 \mu \mathrm{M}$ of hydrogen peroxide and applied with osmotic stress, the relative water content in leaves was maintained high, and the dryness of leaves was reduced, prolonging the vase life of cut leaves. The results were attributed to treating with hydrogen peroxide that induced the generation of antioxidant enzymes, increased the total water soluble sugar content, decreased lipid peroxidation and thus increased their resistance against osmotic stress.

The total chlorophyll content in 'Siberia' lily decreased over time, and that of the groups treated with plasma-activated water was maintained higher than that of the control group. The chlorophyll content in the PAW600 group was maintained highest (Fig. 3C). Browning is one of the early aging symptoms of cut lily flowers, and their vase life is often determined by the life of leaves rather than that of flower perianths (van Doorn and Han, 2011). In this study, the chlorophyll content in cut flowers of 'Siberia' lily was maintained high by treating them with plasma-activated water that contains hydrogen peroxide, and earlier studies on 'Manissa' lily and tuberose also showed similar results (Liao et al., 2012; RahimianBoogar et al., 2016).

\section{The amount of microorganisms generated in the preservative solution treated with plasma-activated water}

The amount of microorganisms generated in the preservative solution for 'Siberia' lily was measured (Fig. 4). Microbial growth in the preservative solution was effectively suppressed by increasing the electric discharge time and the amount of hydrogen peroxide. Plasma-activated water that contained $900 \mu \mathrm{M}$ of hydrogen peroxide reduced the density of general bacteria within the initial preservative solution by 30 times on average compared to that for the control group, and the gap was maintained until after 9 days. When the cut surface of the stem of cut flowers is decayed or when latex is produced from the cut surface, microorganisms propagate and close their stomata, which suppresses water absorption and reduces their vase life (van Doorn, 1997). Preservative solutions are mostly added with a bactericide, and it was reported that treating lily with $150 \mathrm{mg} \cdot \mathrm{L}^{-1}$ of 8-hydroxyquinoline sulfate (HQS) is effective in suppressing microbial growth (van Doorn and Han, 2011). Therefore, preservative solutions using plasma-activated water are expected to contribute to reducing the density of microorganisms, accelerating water absorption and thus improving the quality and vase life of cut 


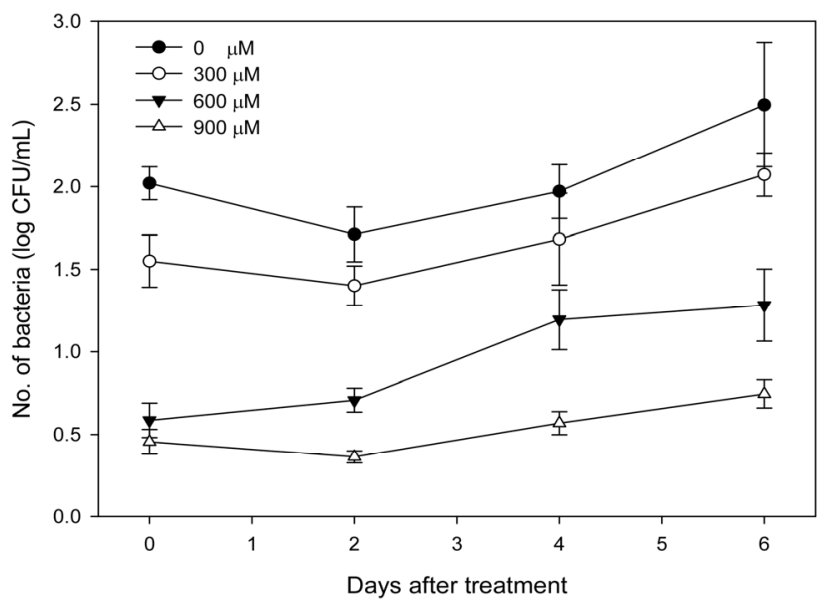

Figure 4. Effects of underwater plasma activated water on the number of bacteria in the preservative solution. Data are the means \pm SD from five replications.

flowers.

These results indicate that treating cut flowers of 'Siberia' lily with a preservative solution using plasma-activated water that contained $600 \mu \mathrm{M}$ of hydrogen peroxide was effective in increasing their flower diameter and ability to absorb water, reducing a loss in fresh weight, maintaining high the relative water content and chlorophyll content in leaves, and thus prolonging the vase life of cut flowers. In addition, since plasma-activated water can suppress microbial growth in preservative solutions, it will be possible to establish an eco-friendly quality control system for cut flowers using the method.

\section{Conclusions}

This study was carried out to identify the effects of plasma-activated water on the postharvest quality of 'Siberia' lily. Changes in the amount of hydrogen peroxide produced using underwater plasma apparatus depending on the electric discharge time were measured. Plasma-activated water that contained 300, 600 and $900 \mu \mathrm{M}$ of hydrogen peroxide was used as a preservative solution. The longer the electric discharge time, the more hydrogen peroxide was produced in plasma-activated water. The vase life of cut flowers of 'Siberia' lily was prolonged by treating them with plasma-activated water compared to that of the control group. In particular, it was found that treating with plasma-activated water that contained $600 \mu \mathrm{M}$ of hydrogen peroxide improved the vase life, maximum flower diameter and water absorption ability of cut flowers, reduced a loss in fresh weight, relative water content and chlorophyll content in leaves. The longer the plasma discharge time and the more hydrogen peroxide was produced, the more effectively microbial growth in the preservative solution was suppressed. Therefore, the use of plasma-activated water that contains $600 \mu \mathrm{M}$ of hydrogen peroxide is expected to suppress the generation of microorganisms in preservative solutions, prolong the vase life of cut flowers, and thus to effectively improve the postharvest quality of cut lily flowers.

\section{References}

De Azevedo Neto, A.D., J.T. Prisco, J. Enéas-Filho, J.V.R. Medeiros, and E. Gomes-Filho. 2005. Hydrogen peroxide pre-treatment induces salt-stress acclimation in maize plants. J. Plant Physiol. 162(10):1114-1122. DOI:10.1016/ j.jplph.2005.01.007 
Fanourakis, D., R. Pieruschka, A. Savvides, A.J. Macnish, V. Sarlikioti, and E.J. Woltering. 2013. Sources of vase life variation in cut roses: a review. Postharvest Biol. Technol. 78:1-15. DOI:10.1016/j.postharvbio.2012.12.001

Gao, Y., Y.K. Guo, S.H. Lin, Y.Y. Fang, and J.G. Bai. 2010. Hydrogen peroxide pretreatment alters the activity of antioxidant enzymes and protects chloroplast ultrastructure in heat-stressed cucumber leaves. Sci. Hortic. 126(1):20-26. DOI:10.1016/j.scienta.2010.06.006

Hong, Y.C., H.J. Park, B.J. Lee, W.S. Kang, and H.S. Uhm. 2010. Plasma formation using a capillary discharge in water and its application to the sterilization of E. coli. Phys. Plasmas 17:053502. DOI:10.1063/1.3418371

Hu, Y., Y. Ge, C. Zhang, T. Ju, and W. Cheng. 2009. Cadmium toxicity and translocation in rice seedlings are reduced by hydrogen peroxide pretreatment. Plant Growth Regul. 59:51-61. DOI:10.1007/s10725-009-9387-7

Lee, C.H. and M.H. Cho. 2013. Understanding plasma. KIPE Mag. 18(3):29-33.

Lee, S.K., T.R. Kwon, E.J. Suh, and S.C. Bae. 2011. Current status of phenomics and its application for crop improvement: Imaging systems for high-throughput screening. Korean J. Breed. Sci. 43(4):165-172.

Liao, W.B., M.L. Zhang, G.B. Huang, and J.H. Yu. 2012. Hydrogen peroxide in the vase solution increases vase life and keeping quality of cut Oriental×Trumpet hybrid lily 'Manissa'. Sci. Hortic. 139:32-38. DOI:10.1016/j.scienta.2012.02.040

Ma, S.H., K.I. Kim, J.Y. Huh, and Y.C. Hong. 2017. Characteristics of microdischarge plasma jet in water and its application to water purification by bacterial inactivation. Sep. Purif. Technol. 188:147-154. DOI:10.1016/j.seppur.2017.07.034

Panavas, T. and B. Rubinstein. 1998. Oxidative events during programmed cell death of daylily (Hemerocallis hybrid) petals. Plant Sci. 133(2):125-138. DOI:10.1016/S0168-9452(98)00034-X

Rahimian-Boogar, A., H. Salehi, and N. Mir. 2016. Influence of citric acid and hydrogen peroxide on postharvest quality of tuberose (Polianthes tuberosa L. 'Pearl') cut flowers. J. Hortic. Res. 24(1):13-19. DOI:10.1515/johr-2016-0002

Saglam, A., E. Kalaycioglu, F.G. Guven, N. Saruhan, A. Kadioglu, and M. Demiralay. 2014. Hydrogen peroxide extends postharvest life of Ctenanthe setosa leaf cuts under osmotic stress by reducing leaf rolling. Hortic. Environ. Biotechnol. 55(4):308-314. DOI: 10.1007/s13580-014-0138-y

Saxena, I., S. Srikanth, and Z. Chen. 2016. Cross talk between $\mathrm{H}_{2} \mathrm{O}_{2}$ and interacting signal molecules under plant stress response. Front. Plant Sci. 7:570. DOI: 10.3389/fpls.2016.00570

Seo, S.G., S.H. Kim, G.P. Lee, and S.W. Kang. 2009. Effect of reactive oxygen species on floral senescence in Hibiscus syriacus L. J. Plant Biotechnol. 36(2):179-183. DOI: 10.5010/JPB.2009.36.2.179

Teixeira da Silva, J.A. 2003. The cut flower: Postharvest considerations. J. Biol. Sci. 3(4):406-442. DOI:10.3923/ jbs.2003.406.442

Uhm, H.S., Y.C. Hong, and D.H. Shin. 2006. A microwave plasma torch and its applications. Plasma Sources Sci. Technol. 15(2):S26-S34. DOI: 10.1088/0963-0252/15/2/S04

van Doorn, W.G. 1997. Water relations of cut flowers. In J. Janick (Ed.), Horticultural Reviews Vol. 18 (pp. 1-85). New York, NY: John Wiley \& Son, Inc.

van Doorn, W.G. and S.S. Han. 2011. Postharvest quality of cut lily flowers. Postharvest Biol. Technol. 62(1):1-6. DOI:10.1016/j.postharvbio.2011.04.013

Yoo, M.H., Y.J. Kim, H.J. Byoun, and K.C. Son. 2003. Effects of certain pretreatment substances on the postharvest quality of cut rose. Korean J. Hortic. Sci. Technol. 21(4):375-380. 